\title{
Tackling grade inflation in US universities
}

Solutions could include reporting the class average and ranking departments by results.

Sir - Your Editorial “Against grade inflation" (Nature 431, 723; 2004) raises an important question in US higher education that affects both the efficacy of our assessments of student performance and the credibility of those assessments.

Back when I was on the other side of the lectern, my impression was that a grade was a statement of relative academic performance. A "C" was actually defined in the academic catalogue as "average", along with " $\mathrm{A}=$ excellent", "B = above average", " $\mathrm{D}=$ below average" and " $\mathrm{F}=$ failure". These days I see that the academic catalogue defines a "C" as "satisfactory" and a "D" as a "minimum passing" grade. This change reflects the lamentable fact that grades no longer hold any real contextual meaning.
I believe that change is long overdue. If professors are too nervous about appeasing students and parents to stick to the definition of "C" as average, then student grades should be reported, as they were at my undergraduate institution, along with the average for the class. So instead of receiving a naked " $B$ ", a student might receive a " $\mathrm{B}-, 3.4 / 3.62$ " — indicating that this student was actually 0.22 grade units below the class average of 3.62 , despite receiving a grade higher than a " $\mathrm{C}$ ".

This approach would work well for universities' internal use, but what about external evaluation? Perhaps US colleges and universities could be ranked using some system analogous to the impact factor of journals, a ranking that might be derived from the performance of its students on standardized national exams.

To avoid potential difficulties, such as ranking a department with a superb record within a mediocre university, it would seem sensible to perform this ranking on a departmental as opposed to a university-wide basis.

In this way, a student could be more or less objectively evaluated by a graduate school or prospective employer as having a "3.44/3.12 grade-point average from a 1.76-ranked US university chemistry department". Wouldn't that be a more scientific approach to measuring student performance in the academic crucible? Craig D. Thulin

Department of Chemistry and Biochemistry, Benson Building, Room C-100,

Brigham Young University, Provo, Utah 84602, USA

\section{Grade inflation: students} seek it, funders reward it

Sir-Your Editorial (Nature 431, 723; 2004) identifies a serious problem, but modifying the use of student evaluations is only a partial solution. Students actively 'shop' for courses with grade inflation.

If money is allocated to departments on the basis of the number of students enrolling on a course, as it is at my university, then grade inflation is rewarded with additional funding.

We need to make courses compete on content rather than grading. One way to level the playing field would be to include students' percentile ranks in each class (for instance, $90 \%$ if only $10 \%$ of students in the class had higher scores) in their transcripts, along with traditional grades. How this might affect competition among universities is an interesting question.

\section{R. Ford Denison}

Agronomy and Range Science, University of

California, 1 Shields Avenue, Davis,

California 95616, USA

\section{Grade inflation keeps the customers happy}

Sir - As your Editorial notes (Nature 431, $723 ; 2004)$, grade inflation is indeed real in the United States, and not only at private institutions. The evidence isn't anecdotal: the data (see www.gradeinflation.com) show that grade inflation is omnipresent at community colleges and at both public and private four-year schools.
Your solutions to this problem could be easily implemented. However, getting things turned around would require university leaders willing to buck the 'keep the customer happy' ethos on US campuses. Unfortunately, such leaders are few and far between. Grade inflation is a symptom of an overarching problem in higher education: a failure of university leadership to have the courage to preserve the integrity of US higher education. Stuart Rojstaczer

Duke University, Box 19302, Stanford, California 94309, USA

\section{Journals must cooperate to defend biosecurity}

Sir - In publishing the Letter to Nature by D. Kobasa and colleagues, "Enhanced virulence of influenza A viruses with the haemagglutinin of the 1918 pandemic virus" (Nature 431, 703-707; 2004), Nature has endorsed a publication that reports the creation of an influenza strain with increased virulence (at least in mice) based on the molecular structures of one of the deadliest diseases of the twentieth century. This will surely bring both benefits and risks to biosecurity.

Following a discussion of the problems arising from the publication of biosecuritysensitive data, scientific journal editors came together and agreed that this issue deserves attention and that some general measures should be in place (see Nature 421, 771; 2003). Since then, most leading journals, including Nature, have introduced procedures to deal with this issue.
However, there are good reasons to believe that these individual journalspecific procedures are inadequate, in that they give the least restrictive journal the ultimate control over sensitive biosecurity information. Looking at the tremendous impact the outcome of the editor's decision may have on the public, informed democratic participation in the decisionmaking process must be a requirement. At present, none of these journals release information on the risk-benefit analysis undertaken in specific cases to allow independent assessments.

As long as clear guidance from legislators is missing, the policies followed by these scientific journals will remain non-transparent, possibly inconsistent and subject to political bias. Let's hope that the initiatives being pursued by several countries, including the United States (www.aaas.org/spp/post911/agents), to negotiate biosecurity guidelines for scientists, will lead to workable and publicly accepted principles regarding all aspects of research, including the publication of research results.

A necessary first step towards transparency could be the publication of the local biosafety committee's reasons for giving approval, the biosafety measures taken and the editor's risk-benefit assessments.

Johannes Rath*, Bernhard Jank*, Otto Doblhoff-Dier $\dagger$

${ }^{\star}$ Department of Theoretical Biology and Developmental Biology, Althanstrasse 14, 1090 Vienna, Austria

$\dagger$ Institute for Applied Microbiology,

University for Agricultural Sciences,

Muthgasse 18, A-1190 Vienna, Austria 